\title{
A EXPERIÊNCIA DA EDUCAÇÃO POPULAR COMO FORMA DE DIÁLOGO COM ESTUDANTES DE ENSINO MÉDIO
}

\author{
A. T. P. Camurça ${ }^{1} \&$ L. C. Vieira ${ }^{2}$
}

${ }^{1}$ Graduanda em Direito pela Universidade Federal do Ceará (UFC). Bolsista da ação extensionista Diálogos para Diversidade. E-mail: tais.camurca1 @ gmail.com; ${ }^{2}$ Graduanda em Direito pela Universidade Federal do Ceará (UFC). Membra voluntária da ação extensionista Diálogos para a Diversidade. E-mail: larissacamurca@gmail.com

Artigo submetido em Setembro/2017 e aceito em Novembro/2017

\section{RESUMO}

O presente trabalho pretende analisar a experiência do Projeto de Extensão Diálogos para Diversidade com a educação popular e abordar como esta forma de ensino e troca de experiências e saberes pode se apresentar como uma porta de entrada para o diálogo com os jovens estudantes. O estudo se concentrará em tratar dos encontros do Projeto que, ao longo do ano de 2017, realizou visitas a duas escolas de ensino público, a Escola Michelson Nóbrega da Silva e a Escola de Ensino Médio Ayrton Senna da Silva, promovendo diálogos que tinham como temática o feminismo, a diversidade sexual, a homofobia e discussões sobre o Movimento Escola Sem Partido, com estudantes do Ensino Médio. No estudo, trataremos sobre como a Educação Popular, que se apresentou como uma importante ferramenta para a construção da formação política e cidadã desses jovens estudantes, ao estimular o olhar crítico e o diálogo como forma de analisar melhor o panorama social e político-econômico que se apresenta na atualidade. A metodologia utilizada foi a análise bibliográfica, o relato de experiência e a reflexão crítica. Foi possível notar, com esse trabalho, que, por estes jovens estarem se formando como cidadãos em um período de transformações de grandes instabilidades no que se refere à política e direitos humanos, a abordagem que foi utilizada, a qual valoriza o saber popular e os saberes prévios dos sujeitos envolvidos, conseguiu se inserir em suas experiências como uma importante forma de aquisição de conhecimento e afirmação como sujeitos políticos e sociais atuantes.

PALAVRAS-CHAVE: Direitos Humanos, Educação Popular, Gênero, Feminismo.

\section{THE EXPERIENCE OF POPULAR EDUCATION AS A FORM OF DIALOGUE WITH HIGH SCHOOL STUDENTS}

\footnotetext{
ABSTRACT

The present study intends to analyse the experience of the Extension Project Diálogos para Diversidade with the Popular Education and explain how this way of teaching and exchanging experiences and knowleges can be an effective approach on the dialogue with young students. The study will be concentrated in the analysys of the visits that were made, among the year of 2017 , by the Project, in two public schools: Escola Michelson Nóbrega da Silva
}

and Escola de Ensino Médio Ayrton Senna da Silva, on which we promoted discussions that involved themes like feminism, sexual diversity, homophobia and the Moviment Escola Sem Partido, with high school students. In the study, we will explain how the popular education, which was an important tool for the construction of the social conscience of these young students, while encouraging the critic vision and the dialogue as a way of better analysing the 
political, social and economical realities. The method that was used was the bibliographic research, the experience report and the critic reflexion. It can be concluded, with this work, that, because the students are growing up and getting their consciences in a period full of instabilities and fragilities in the area of politics and human rights, the approach that was made, which valorized the popular knowledge the previous knowledge of the sujects involved, was inserted in their experiences as an important way of absorbing knowledge and seeing themselves as active political and social subjects.

KEYWORDS: Human Rights, Popular Education, Gender, Feminism.

\section{INTRODUÇÃO}

É inegável que, nas últimas décadas, a sociedade contemporânea tem passado por grandes e importantes mudanças. Houve inúmeros períodos de efervescências políticas, grandes movimentações de diferentes grupos sociais, vários tipos de oscilações na economia, uma grande gama de inovações tecnológicas, entre outros. E é evidente que tais mudanças de diversas facetas afetam a mentalidade dos indivíduos que vivem nessa sociedade. A mentalidade de indivíduos que nasceram na década atual, por exemplo, se difere imensamente da mentalidade de pessoas nascidas a 20, 30 anos atrás. Tudo o que foi explanado aqui se condensa na constatação de que: a sociedade mudou e juntamente com ela as concepções de realidade dos indivíduos integrantes dela.

Analisado nesse contexto, o ambiente escolar aparece como integrante da sociedade. Ora, as escolas não são nichos isolados do restante da coletividade, elas fazem parte dela e, em consequência disso, sofrem também as mesmas mudanças que ela sofre. Ou seja, durante esses períodos de mudanças e transformações sociais, os ambientes de aprendizado não restaram imunes à essa situação, todas as vicissitudes que aconteceram nas últimas décadas também se realizaram dentro das escolas, atingindo seus membros docentes e discentes.

Tendo isso em vista, o que se percebe é que, com tudo o que tem acontecido na sociedade, o modelo de ensino precisa se adaptar ao atual panorama social e buscar todos os instrumentos necessários para que os estudantes se tornem agentes capazes de transformar, também, a sociedade. Esse é o grande desafio da educação atual: entender as movimentações sociais que rodeiam o ambiente escolar e, além disso e principalmente, contemplá-las e incluílas no sistema de ensino a ser utilizado.

Tal necessidade é acentuada no contexto das escolas públicas, uma vez que sua 
responsabilidade para com a sociedade é maior e que os sujeitos frequentadores dessas escolas merecem uma atenção dobrada. É fato, infelizmente, que, para os indivíduos integrantes das camadas sociais menos privilegiadas, todos os impactos sociais provenientes de mudanças são sentidos de forma mais intensa. Oscilações econômicas, conflitos sociais, e efervescências políticas sempre atingem mais fortemente os indivíduos marginalizados da sociedade. Alguns agentes maiores destas transformações, inclusive, muitas vezes, se aproveitam de indivíduos marginalizados que ignoram certas questões para mitigar muitos de seus direitos. As escolas públicas aparecem, então, como ambientes de extrema importância, uma vez que tais grupos sociais necessitam ter conhecimento e se apropriarem de certos temas para se inserirem como seres atuantes e transformadores dentro da sociedade, de forma não serem omissos ou passivos em situações onde são os seus direitos e prerrogativas que estão em questão.

É fato, então, que os grupos sociais de menor poder aquisitivo e estudantes de escolas públicas merecem uma maior atenção, no que diz respeito à aprendizado e educação. E em face disso, as escolas públicas, por atuarem diretamente com estes sujeitos, têm o dever de promover um método de ensino que integre também os problemas da sociedade atual e superar cada vez mais do modelo antigo e tradicional de ensino fragmentado e distanciado da realidade.

O que os estudantes precisam, nesse contexto, é de um sistema que possua uma concepção de mundo, de sociedade, de aprendizado e de conhecimento que se adeque à realidade social a qual eles estão inseridos, uma realidade na qual, cada vez mais, grupos de minorias historicamente isolados emergem e a tornam mais diversa. A escola, então, deve munir os seus professores com ferramentas e instrumentos eficazes para que possam intermediar efetivamente a aquisição do conhecimento científico que os alunos devem adquirir, e, ao mesmo tempo, valorizando e reconhecendo o conhecimento prévio dos alunos. É necessário desafiar os alunos, levá-los a pensar e refletir sobre todos os tipos de questões sociais relevantes, para que, ao fazer isso, consigam se tornar sujeitos ativos no processo de construção de sua sociedade mais igualitária e humana.

A construção do conhecimento na Educação Contemporânea deve ocorrer coletivamente e estar voltada para questões que contemplem as diferenças, ou seja, a diversidade humana que compõe a escola, sendo necessário para isso, incluir questões a serem discutidas e/ou refletidas tais como: etnia, raça, gênero, classe, sexo, entre outras, valorizando todo o conhecimento que os diferentes grupos trazem para a sala de aula, enriquecendo muito mais o ensino e a aprendizagem, onde, infelizmente acabam sendo despercebidos ou ignorados por muitos 
professores. (SANTOS, 2008, p. 10)

Entretanto, o que é observado hoje, em muitos ambientes de aprendizado, é que ainda se conserva um modelo de educação ultrapassado, no qual se afirmam tendências pedagógicas que perenizam um modelo de ensino homogeneizado e que não dá atenção às diferenças. Ora, os perigos dessa perpetuação se tornam claros ao observarmos que a comunidade escolar é composta por integrantes de diferentes grupos sociais, políticos, étnicos, religiosos, etc. Logo, a reflexão sobre essa diversidade em sala de aula se mostra um elemento de enorme importância para o alcance de uma efetiva transformação prática e cultural das escolas.

Os educadores, então, devem assumir seu papel de agentes importantes para estas transformações e buscar mediar as aprendizagens de uma maneira que seja incorporada uma concepção que considere a diversidade e desconsidere a exclusão, colaborando para a construção de um ambiente escolar livre de preconceito.

Foi com essa concepção em mente que os membros do Projeto Diálogos para Diversidade levaram uma série de debates relevantes para as salas de aula de duas Escolas Públicas.

\section{DESENVOLVIMENTO}

\subsection{A EDUCAÇÃO POPULAR COMO INSTRUMENTO UTILIZADO}

Diante de todas essas problemáticas referentes ao modelo de educação contemporâneo, suas peculiaridades e como ele deve se delinear, a Educação Popular emerge como uma solução ideal de todas essas questões adversas. E foi nela que o Projeto Diálogos para Diversidade se pautou ao pensar nas metodologias usadas nos debates e pontos que foram debatidos nas Escolas de Ensino Médio que foram visitadas.

A Educação Popular foi abordada, originalmente, nas obras de Paulo Freire, durante a década de 60, e criou o paradigma de uma prática pedagógica diferente, na qual o diálogo é o ponto principal e os saberes de todos os envolvidos são valorizados, com o fito de alcançar uma construção coletiva de aprendizado. Não sendo o professor o único a ensinar e não sendo o aluno o único a aprender. O conhecimento não é passado de uma maneira unilateral. Conforme o próprio autor já afirmava em suas obras: "ninguém educa ninguém, ninguém educa a si mesmo, os homens se educam entre si, mediatizados pelo mundo". 
Assim, percebe-se que a educação popular surge para superar o sistema de ensino tradicional, no qual é, muitas vezes, ignorado o elemento-chave para uma educação humanizada: o diálogo. Acabando por se tornar um método pedagógico que não instiga, interessa ou desafia os alunos a terem uma visão mais crítica dos assuntos levados à sala de aula que fazem parte da realidade que os rodeia. Paulo Freire, ao tratar desse modelo de aprendizado, se utilizava da palavra "Educação Bancária":

Desta maneira, a educação se torna um ato de depositar, em que os educandos são os depositários e o educador o depositante. Na visão "bancária" da educação, o "saber" é uma doação dos que se julgam sábios aos que julgam nada saber. Doação que se funda numa das manifestações instrumentais da ideologia da opressão a absolutização da ignorância, que constitui o que chamamos de alienação da ignorância, segundo a qual esta se encontra sempre no outro. (FREIRE, 1970, p. 66 -67)

É essa concepção "bancária" que Freire aborda a que se encontra perpetuada, infelizmente, em muitas das escolas públicas do território brasileiro, na qual os professores não se utilizam do diálogo e nem se importam em transformar a prática pedagógica numa via de mão dupla aonde se cria um espaço organizado de troca de conhecimentos e aprendizados para o amadurecimento de ideias e a formação de alunos conscientes do seu poder de transformação. Os educadores, nesse sistema de educação, apenas "entregam" um conhecimento pronto para que os educandos o repitam e o memorizem. Acaba por se delinear uma hierarquização do conhecimento, onde o saber trazido pelo educador se mostra mais importante e valorizado do que o conhecimento popular que os alunos possuem, por meio de suas experiências. Não há diálogo, não há transformação, não há um verdadeiro aprendizado.

Um método pedagógico que englobe a educação popular é imprescindível para que os educandos e escolas da rede pública possam vivenciar uma experiência de real aprendizado político, crítico, transformador e consciente. Principalmente em um momento como o atual, no qual são inúmeras as questões e conflitos latentes que emergem na sociedade e precisam ser levadas também às salas de aula. A educação é o instrumento capaz de transformar o que precisa ser transformado, de moldar um futuro de mudança e de diversidade, e de construir, enfim, uma comunidade democrática, tolerante e cidadã. Fiori corrobora com essa visão:

O método de Paulo Freire é, fundamentalmente, um método de cultura popular: conscientiza e politiza. Não absorve o político no pedagógico, mas também não põe inimizade entre educação e política. Distingue-as, sim, mas na unidade do mesmo movimento em que o homem se historiciza e busca reencontrar-se, isto é, busca ser livre. Não tem ingenuidade de supor que a educação, só ela, decidirá dos rumos da história, mas tem, contudo, a coragem suficiente para afirmar que a educação verdadeira conscientiza as contradições do mundo humano, sejam 
estruturais, superestruturais ou inter-estruturais, contradições que impelem o homem a ir adiante. (FIORI in FREIRE, 1982, p. 15).

Em face disso, nota-se o porquê de o Projeto ter escolhido a abordagem da educação popular de Paulo Freire para discutir com os alunos das escolas visitadas sobre as temáticas escolhidas.

\subsection{A QUESTÃO DE GÊNERO NAS ESCOLAS}

A Constituição Federal de 1988, em seu art. $6^{\circ}$, assegura que a educação é um direito de todos e, em seu art.206 , I, estabelece como princípio norteador da educação a igualdade de condições para acesso e permanência na escola. E sabe-se que, como já foi abordado, a comunidade escolar, atualmente, é constituída por diversos e variados grupos étnicos, religiosos, sociais, políticos, etc.

O problema a ser enfrentado aqui não é o do acesso das mais diferentes camadas sociais à educação, uma vez que é notório que, atualmente, é amplo o acesso dos diversos indivíduos às escolas públicas, independentemente do grupo ao qual pertence. $\mathrm{O}$ que se discute aqui e o que aparece como a grande problemática a ser discutida é a questão da permanência. Ora, como se poderia afirmar que as condições de permanência na escola são asseguradas igualmente para todos os indivíduos quando o que acontece na realidade de muitos é o contrário? O fato é que por mais que exista a diversidade no âmbito escolar, isso não significa que as escolas saibam se adaptar e lidar bem com essas diferenças.

Os indivíduos que não se adaptam aos parâmetros de feminilidades, masculinidades e orientações sexuais encarados como normais, de acordo com os padrões sociais dominantes, são frequentemente expostas, no ambiente escolar, a agressões físicas e verbais, a violações de direitos e discriminações de todo tipo. Suas diferenças se transformam em reais desigualdades.

E é essa a maior problemática a ser trazida nesse tópico: a falta de sensibilidade e preparo de muitas escolas, que é o que, muitas vezes, leva muitos alunos a terem a sua permanência nestes ambientes conturbada, afetada e até interrompida pelo preconceito vivido nesse ambiente. Os dados estatísticos são claros a denotar essa realidade: 
Estudo realizado pela Secretaria de Educação da Associação Brasileira de Lésbicas, Gays, Bissexuais e Transexuais (ABLGBT), divulgado em dezembro de 2016, mostra que $73 \%$ dos estudantes que não se declaram heterossexuais no Brasil já foram agredidos verbalmente na escola. Já as agressões físicas ocorreram com um a cada quatro desses alunos. Na Pesquisa “Juventudes Na Escola, Sentidos e Buscas: Por Que Frequentam?”, de 2015, cerca de $20 \%$ dos alunos pesquisados, afirmaram que o tipo de estudante com o qual eles não gostariam de ter contato em sala de aula são os estudantes homossexuais, travestis e transgêneros.

Devido ao preconceito que vivem dentro das escolas, muitos desses indivíduos, sobretudo travestis e transexuais, se veem obrigados a se retirar desses ambientes e, em decorrência disso, permanecem com baixa escolaridade. E isso os afeta mais ainda no que se refere ao mercado de trabalho, porquanto essa baixa escolaridade e a exclusão também existentes nesse âmbito, constantemente, não permitem que essas pessoas consigam boas oportunidades. Em decorrência disso, os dados também são alarmantes, segundo dados da ANTRA [Associação Nacional de Travestis e Transexuais], mais de $90 \%$ de travestis e transexuais vivem unicamente da prostituição.

A questão de gênero dentro das escolas não se limita aos casos de pessoas LGBT, é necessário que se destaque, também, a questão do preconceito e da exclusão também contra as mulheres, que, historicamente, sempre estiveram numa posição desprivilegiada na sociedade. Essa visão da mulher já vem sendo desmitificada em virtude das transformações e conquistas alcançadas pela luta de diversas mulheres ao longo da história que permitiram que as mulheres pudessem, finalmente, ocupar os mesmos espaços que os homens. Contudo, é claro que todo esse preconceito perpetuado historicamente ainda se manifesta hoje em diversas áreas, como na política e no mercado de trabalho, onde as proporções entre homens e mulheres ainda são discrepantes. Tal mentalidade de preconceito deveria ser evitada, desde cedo, no âmbito das escolas, mas, infelizmente, não é o que ocorre.

Uma pesquisa do Ministério da Educação (MEC), divulgada em 2010, mostra que, na escola, o preconceito de gênero manifesta-se com mais força do que todos os outros, inclusive de cor e opção sexual. O estudo, produzido pela Fundação Instituto de Pesquisas Econômicas da Universidade de São Paulo (Fipe-USP), revelou que cerca de $20 \%$ dos alunos passaram por 
situações ou presenciaram cenas em que alguma menina foi humilhada pelo simples fato de ser menina. No ensino médio, quase metade dos 15 mil alunos ouvidos afirmam que certos trabalhos só podem ser realizados por homens.

São as prerrogativas constitucionais do acesso à educação e das condições de permanência nas escolas que estão sendo retiradas desses indivíduos. A falta de capacitação de professores e profissionais destes ambientes é um fator agravante dessa situação, frequentemente educadores se omitem e calam perante uma situação de agressão verbal ou física proveniente de preconceito que acontece nas dependências da escola. Há casos, inclusive, em que são os próprios educadores os que destilam preconceito com esses indivíduos, quando, por exemplo, se recusam a chamar os alunos transsexuais por seu nome social ou quando encorajam a prática de brincadeiras machistas e homofóbicas em sala de aula.

Frente a essa realidade, torna-se necessário que a educação se volte também para a desconstrução desses tipos de estereótipos e exclusões com as diferenças de gênero e sexuais, se utilizando de práticas pedagógicas que possibilitem a inclusão de todos os indivíduos,

sejam eles homens ou mulheres, heterossexuais, homossexuais, transgeneros, etc. É preciso que os estudantes possam obter uma educação humanizada, por meio da capacitação dos profissionais envolvidos, calcada na igualdade e na tolerância, que foque na conscientização e na sensibilização para a aceitação de diversidades.

\subsection{O PROJETO E SUAS DISCUSSÕES}

Ao longo do ano de 2017, foram realizadas as visitas do Projeto Diálogos para Diversidade em duas Escolas Públicas: a Escola de Ensino Fundamental e Médio Michelson Nobre da Silva e a Escola de Ensino Médio e Tempo Integral Ayrton Senna da Silva. Cada encontro foi realizado no período da tarde, com turmas mistas do $2^{\circ}$ e $3^{\circ}$ ano do Ensino Médio, e mediado pelos membros do Projeto de Extensão. Foi preparada uma mesma metodologia para ser utilizada nos dois encontros, pautada em todos os conceitos de educação contemporânea e popular já abordados anteriormente, para tratar dos temas selecionados: a educação popular e a diversidade sexual e de gênero. 
É importante esclarecer como se deu o processo de elaboração da metodologia. A principal preocupação dos membros do projeto era conseguir levar a formação de forma que os alunos se sentissem a vontade para expressar suas opiniões e falar sobre suas vivências, para assim não nos colocarmos como os detentores da razão, mas mostrar que todas as experiências devem ser valorizadas e que é assim que se constrói o conhecimento. Nessa perspectiva, enfrentamos a dificuldade de conseguir adaptar a linguagem utilizada durante a formação para que ficasse acessível a todos, já que iríamos falar sobre temas que, muitas vezes tem uma linguagem própria, como o processo de elaboração e efetivação de leis, pois, em muitos casos, os jargões jurídicos, apesar de serem bem compreendidos pelos membros do Projeto, não o são por pessoas que não atuam nesse meio.

Tentamos lidar com essas questões propondo uma metodologia com muitos espaços para debates e discussões, procurando fazer perguntas que estimulassem os jovens a expressar suas opiniões e tendo sempre o cuidado de procurar perceber se as nossas falas estavam sendo entendidas por todos, buscamos usar uma linguagem simples, fazendo o uso de metáforas e esclarecendo de forma descomplicada todas as dúvidas que surgiam durante o debate.

No início dos dois encontros, foi feita uma rodada de apresentações para que os membros do Projeto pudessem se familiarizar com os alunos com os quais iam dialogar, na qual os alunos se apresentavam, falando seus nomes, idades e em que série estavam matriculados e outras atividades que praticavam na escola. Empós, foi feita uma análise, junto com os estudantes presentes, do Projeto de Lei Escola Sem Partido. Foram apresentadas as propostas que esse projeto traz e ocorreu uma discussão sobre que consequências ele causaria na rotina das escolas e na relação entre alunos e professores de forma prática. Ademais, foi perguntado aos alunos qual era o conceito de educação. $\mathrm{O}$ diálogo que se seguiu foi bastante enriquecedor, o espaço de fala predominante foi dos estudantes, que apresentaram seus conceitos de educação: troca de conhecimentos, aprendizado, leitura, preparação para a "vida lá fora", etc.

Depois desse intervalo de debate onde foram ouvidos os conceitos trazidos pelos estudantes, os membros do Projeto iniciaram uma explanação sobre a Educação Popular, os desafios ainda presentes para o alcance de um modelo pedagógico humanizado e a necessidade de um sistema de ensino que estimulasse os alunos a buscar uma percepção mais 
crítica da realidade como forma de se afirmar como sujeitos capazes de transformações sociais.

Foi notado e apontado por alguns dos alunos, após essa explicação, que muitos dos conceitos de "educação" que foram trazidos por eles no debate anterior se encaixavam naquele modelo proposto pela educação popular e se distanciavam daquele apresentado pelo Escola Sem Partido. A junção do conhecimento levado pelos membros do Projeto com aquele conhecimento já existente nos estudantes possibilitou a construção de ótimos espaços de troca de ideias, conceitos, informações e afetivo aprendizado.

Após isso, foi proposto o debate sobre diversidade sexual e de gênero, no qual foi levantada a questão do machismo e da desigualdade entre homens e mulheres ainda existente e também a da violência vivida por pessoas LGBT dentro do ambiente escolar. Quando tais questões foram levantadas, foi notória a empolgação dos alunos para se manifestar sobre essa temática. A maioria expressou opiniões negativas acerca do preconceito e alguns até se posicionaram de maneira contrária, o que acalorou ainda mais o diálogo. Alguns alunos tiveram oportunidade de relatar suas experiências já vividas com esse tipo de preconceito e receber o apoio dos membros e de seus colegas de classe.

\section{CONCLUSÃO}

Após as formações, os membros do Projeto Diálogos Para a Diversidade fizeram a avaliação dessa atividade. Entendemos que os objetivos pretendidos com as formações foram, em sua maioria, atingidos. A participação dos alunos foi notória e foi observado que, a partir do momento em que eles realmente se sentiram ouvidos e notaram que suas opiniões eram levadas em consideração durante o debate, a empolgação em participar se mostrou cada vez maior.

Outro aspecto avaliado positivamente foi a escolha dos temas a serem trabalhados durante as formações. Decidimos falar sobre temas que fazem parte da realidade social de todos aqueles sujeitos, como é o caso da diversidade sexual e de gênero, mas que são, muitas vezes, negligenciados pela educação formal oferecida nas escolas. Tal situação acaba por deixar muitos alunos tímidos para se pronunciar sobre essas questões e, desse modo, alimenta 
um ciclo de desinformação, medo e preconceito. Além disso, procuramos levar temas políticos atuais que influenciam a dinâmica da escola e precisam ser debatidos pelos sujeitos que a compõem, como é o caso do movimento Escola Sem Partido, questão a qual eles não conheciam de forma aprofundada. Esses temas se mostraram muito proveitosos e incentivaram a participação ativa dos alunos.

Avaliamos também que o diálogo com os estudantes e a oportunidade de ouvir suas experiências trouxe um engrandecimento ao Projeto, pois conseguimos conhecer e entender uma realidade que não é a nossa, mas que se faz presente na vida de diversos jovens brasileiros. Desse modo, foi possível entender as demandas daquele grupo social e tentar contribuir com o saber adquirido na nossa trajetória na universidade pública, de maneira a conscientizar esses jovens de que eles têm, sim, todas as condições adequadas para se tornarem sujeitos sociais ativos e capazes de transformar a realidade em que vivem.

Por fim, concluímos que o diálogo entre os alunos do ensino superior e os do ensino médio têm muito a acrescentar à formação de todos os indivíduos envolvidos nesse processo. A atuação por meio das formações nas escolas públicas se revelou como um método bastante eficiente de construir essa ponte de diálogo. Assim, o Projeto Diálogos para Diversidade pretende realizar esse tipo da ação mais regularmente, de forma a aumentar o alcance para cada vez mais escolas e alunos e promover a interação dos conhecimentos da universidade e das escolas. Tudo isso com o fito de participar na produção e na transmissão de um saber cada vez mais voltado para a realidade social.

\section{REFERÊNCIAS}

ABRAMOVAY, Miriam (Coord.). Juventudes na escola, sentidos e buscas: Por que frequentam?. Brasília-DF: Flacso - Brasil, OEI, MEC, 2015. 346 p. Disponível em: $<$ http://flacso.org.br/files/2015/11/LIVROWEB_Juventudes-na-escola-sentidos-ebuscas.pdf >. Acesso em: 18 set. 2017.

BRASIL, Amcham. Transgênero, transexual, travesti: os desafios para a inclusão do grupo no mercado de trabalho. Estadão, abr. 2017. Disponível em: $<$ http://economia.estadao.com.br/blogs/ecoando/transgenero-transexual-travesti-os-desafiospara-a-inclusao-do-grupo-no-mercado-de-trabalho/>. Acesso em: 18 set. 2017. 
BRASIL. Constituição (1988). Constituição da República Federativa do Brasil. Brasília, DF: Senado Federal: Centro Gráfico, 1988. 292 p.

FREIRE, Paulo. Pedagogia do Oprimido. 17. Ed. Rio de Janeiro: Paz e Terra, 1987. Disponível em: <http://www.dhnet.org.br/direitos/militantes/paulofreire/paulo_freire_pedagogia_do_oprimid o.pdf>. Acesso em: 18 set. 2017.

LINHARES, Luciano Lempek. Paulo Freire: por uma educação libertadora e humanista. In: Congresso Nacional de Educação, 8., 2008, Curitiba. Anais eletrônicos... Curitiba-PR, Champagnat, $2008 . \quad$ Disponível em: <http://www.pucpr.br/eventos/educere/educere2008/anais/pdf/729_522.pdf>. Acesso em: 18 set. 2017.

Machismo na escola: como esse comportamento interfere a vida adulta. Cláudia, out. 2016. Disponível em: <https://claudia.abril.com.br/sua-vida/machismo-na-escola-como-essecomportamento-interfere-a-vida-adulta/>. Acesso em: 18 set. 2017.

SANTOS, Ivone Aparecida dos. Educação para a diversidade: uma prática a ser construída na Educação Básica. Programa de Desenvolvimento Educacional do Estado do Paraná, Cornélio Procópio - PR, 2008.

TOKARNIA, Mariana. Mais de um terço de alunos LGBT sofreram agressão física na escola, diz pesquisa. Agência Brasil, nov. 2016. Disponível em: <http://agenciabrasil.ebc.com.br/educacao/noticia/2016-11/mais-de-um-terco-de-estudanteslgbt-ja-foram-agredidos-fisicamente-diz>. Acesso em: 18 set. 2017. 